\title{
dsPIC based SPWM controlled Three Phase Inverter Fed Induction Motor Drive
}

\author{
Sandip A. Waskar \\ Department of Electronics \\ Technology, Shivaji University \\ Kolhapur.
}

\author{
U. L. Bombale,PhD. \\ Department of Electronics \\ Technology, Shivaji University \\ Kolhapur.
}

\author{
Tanaji B. Sonawane \\ Modern College of Science, \\ Pune.
}

\begin{abstract}
The induction motor fulfills admirably the requirements of substantially constant speed drive. This paper presents simulation and development of variable frequency drive by keeping constant voltage-frequency ratio of power supply which is fed to induction motor. A rule-based fuzzy logic controller applied to a scalar closed loop V/f induction motor (IM) speed control,in MATLAB environment. A fuzzy control system uses speed error and speed error variation to change both amplitude and frequency of supplied voltage. Reference speed and load torque variations are also simulated and implemented on hardware.
\end{abstract}

\section{Keywords}

SPWM inverter, Fuzzy logic, Simpower system, VSI, dsPIC etc.

\section{INTRODUCTION}

Three-phase Induction Motors are widely applied in several industrial sectors for applications such as HVAC (heating, ventilation and air-conditioning), industrial drives (motion control, robotics), automotive control (electric vehicles), etc. In the world which is facing severe energy crisis, the golden rule is "energy saved is energy generated." Use of variable speed drives for industrial applications is one way to generate energy [1].

Extensive use of this motor is mainly due to its simple and rugged structure, adaptation to several load situations and low cost acquisition and maintenance [2]-[6]. Many motor applications, however, require multiple speeds or adjustable speed ranges.

With vector control, VFD gives better dynamic performance [7]-[12]. However, scalar control is characterized by low steady state error and simple in structure for implementation. Therefore, the constant voltage-frequency (V/f) scalar control system is considered due to its large application in industrial fields [13].

In constant V/f control strategy for induction motor, a PI controller is commonly employed [14]. To implement conventional control, the model of the controlled system must be known. The usual method of computation of mathematical model of a system is difficult. When there are system parameter variations or environmental disturbance, the behavior of the system is not satisfactory. Usually classical control is used in electrical motor drives. The classical controller designed for high performance increases the complexity of the design and hence the cost [15].

Advanced control based on artificial intelligence technique is called intelligent control. Every system with artificial intelligence is called self-organizing system. The high power, high speed and low cost modern processors like DSP, FPGA and ASIC IC's along with power technique switches like IGBT made the intelligent control to be used widely in electrical drives[16].

Fuzzy-based control methodology has the ability to cope with system nonlinearity and its control performance is less affected by system parameter variations. Moreover, fuzzy techniques utilize a linguistic rule base which is designed by taking advantage of system qualitative aspects and expert knowledge for motor applications is going to be used in this work [17]. The fuzzy control algorithm is implemented in dsPIC 30F2010.

\section{DEVELOPED CONTROL SYSTEM}

As synchronous speed is directly proportional to supply frequency, speed control is carried out by keeping voltage to frequency ratio constant in order to maintain air gap flux constant. If the supply frequency is varied without voltage adjustment, the induction motor operates in the flux saturation region or in the field weakening region. The figure-1 shows implemented control system.

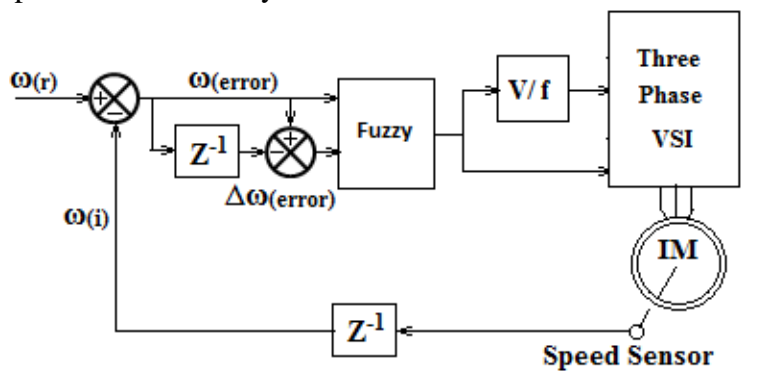

Fig 1: Fuzzy control system for IM speed control

To figure out angular speed for frequency measurement, the generated opto-isolator pulses are given to PIC microcontroller to produce corresponding analog voltage. Actual measured frequency $\omega(\mathrm{i})$ is compared with set point $\omega(\mathrm{r})$. Fuzzy logic works on two inputs speed error $\omega$ (error) and speed error variation $\Delta \omega$ (error), provides sinusoidal PWM frequency. Motor PWM module of dsPIC 30F2010 is accountable for generating PWM signals to six IGBT's of VSI, with $12.5 \mathrm{kHz}$ switching frequency. Controller is also characterized by ADC 12 bit resolution, used to measure load current. VCEsat is monitored to activate short circuitprotection circuitry and Vdc controller turns on to maintain dc voltage level. Pre-charging resistor logic activates when dc link capacitors are fully discharged.

\section{FUZZY LOGIC CONTROL}

Fuzzy logic, a mathematical system developed by Zadeh [18], helps to reduce the complexity of controlling systems. Fuzzy logic expresses operational laws of a control system in 
linguistic terms instead of the traditionally used mathematical equations.

In this induction machine model, normalized values of two inputs in the form of speed error (e) and speed error variation $(\Delta \mathrm{e})$ and defuzzified value of frequency as an output are considered. Basically, Fuzzy system includes three processes: a) Normalization b) Fuzzification and c) Defuzzification. For defuzzification centroid method and for fuzzification mamdani method is used.

\subsection{Fuzzification}

It is the process of mapping crisp inputs to fuzzy membership functions. Figure 2 shows the input and output crisp variables

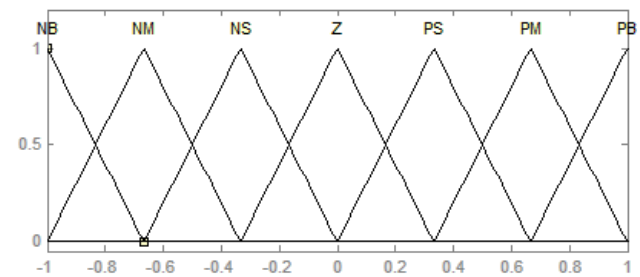

a) input variable "error"

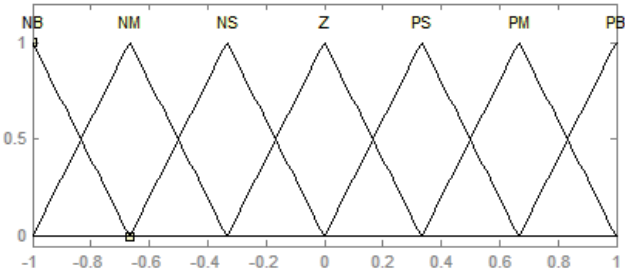

b) input variable "error_diff"

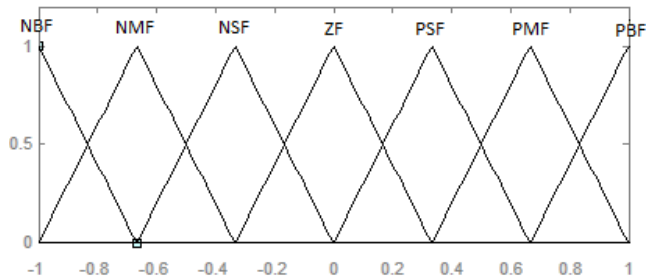

c) output variable "frequency"

Fig.-2. a) \& b) are membership functions of input variables error and error_diff and c) membership function of output variable

\subsection{Inference rule definition}

After defining the membership functions, generate the fuzzy rule definitions to relate the output actions of the controller to the observed sensor inputs. The rule definition is usually in the form of IF THEN statements, but the rules can also be shown in the table format.

Because the rules are based on linguistic terms instead of mathematical equations, any relationship can be defined by a fuzzy logic controller. This also means that even nonlinear systems can be described and controlled with a fuzzy logic controller.

\begin{tabular}{|c|c|c|c|c|c|c|c|c|}
\hline & \multicolumn{1}{|c|}{$\Delta$} & \multirow{2}{*}{ NB } & NM & NS & ZE & PS & PM & PB \\
\cline { 1 - 6 } e & Freq & & & & & & & \\
\hline NB & NBF & NBF & NMF & NMF & NSF & NSF & ZEF \\
\hline NM & NBF & NMF & NMF & NSF & NSF & ZEF & PSF \\
\hline NS & NMF & NMF & NSF & NSF & ZEF & PSF & PSF \\
\hline ZE & NMF & NSF & NSF & ZEF & PSF & PSF & PMF \\
\hline PS & NSF & NSF & ZEF & PSF & PSF & PMF & PMF \\
\hline PM & NSF & ZEF & PSF & PSF & PMF & PMF & PBF \\
\hline PB & ZEF & PSF & PSF & PMF & PMF & PBF & PBF \\
\hline
\end{tabular}

\subsection{Defuzzification}

There are several methods available to obtain a crisp output from a fuzzy system. The most commonly used methods are

a) Maximum defuzzification method

\section{b) Centroid calculation defuzzification method}

The maximum defuzzification method simply selects the rule which satisfies the maximum relative membership when more than one rule is active. The output is then set to the value specified by the selected rule. In this simulation, the Centroid defuzzification method is used to set the output variable.

The stages as fuzzification, rule set and defuzzification is formulated using the fuzzy inference machine of matlab. Then the fuzzy FIS matrix is formed by exporting this FLC into workspace.

The result of the defuzzification has to be a numeric value that determines the v/f ratio to drive three phase induction motor. There are many ways to perform defuzzification; in this case, crisp output is obtained by weighted average defuzzification technique described by equation (1)

$$
\text { Dfuzz }=\frac{\sum_{\mathrm{i}=1}^{9} \mathrm{P}[\mathrm{i}] \mathrm{W}[\mathrm{i}]}{\sum_{\mathrm{i}=1}^{9} \mathrm{~W}[\mathrm{i}]}
$$

$P[i]$ is the peak value of $i^{\text {th }}$ output membership function. $W[i]$ is the weight associated with $\mathrm{i}^{\text {th }}$ rule.

\section{SIMULATION RESULTS}

Induction motor is modeled in phase variable, in order to observe its dynamic behavior irrespective of set point and load variation in MATLAB environment. At the start motor runs with $900 \mathrm{RPM}$ at no load for $2 \mathrm{sec}$. On 2nd sec, motor carries full load of $10 \mathrm{~N}-\mathrm{m}$. Resulting decreased speed is maintained by fuzzy controller; subsequently reference speed command sets RPM to 1400 at $3 \mathrm{sec}$ which is tracked by controller as per knowledge based linguistic rules.

Step response of 1400 RPM reference speed with no load to full load condition is shown respectively in figure (3-a) and (3-e). Responses have drawn for $4 \mathrm{sec}$ that motor speed is according to set RPM. During no load, driver with fuzzy controller shows faster response without any overshoot.

Table 1.Rule Based Matrix for fuzzy controller 

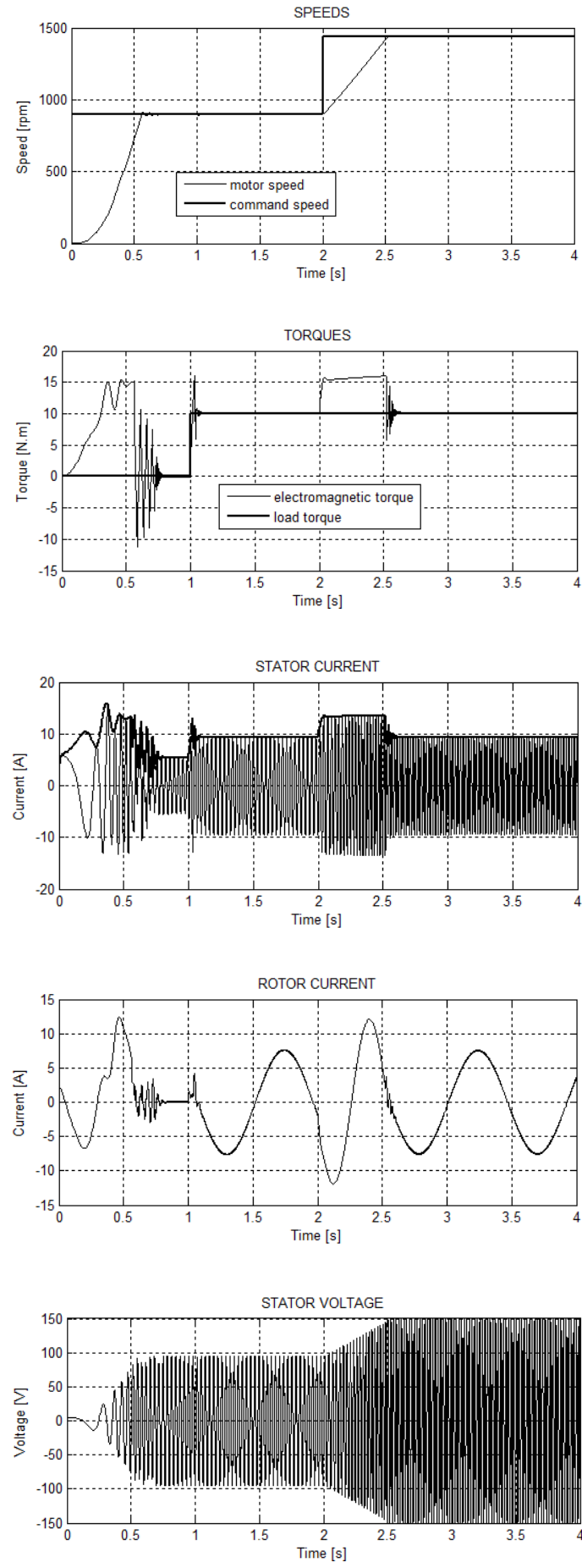

Fig (3-a) to (3-e) shows speed, torque, stator current, rotator current and stator voltage respectively.

\section{HARDWAREIMPLEMENTATION}

Three phase full bridge voltage source inverter (figure 4-a) topology is used with snubber protection. Capacitor precharging circuit turns on, as are fully discharged or below minimum voltage level. In breaking or regenerating mode, dc voltage level exceeds maximum range and is dumped through breaking resistor. On account of RDS ON, IGBT short circuit condition is avoided. Speed set point is entered through keypad, and actual measured speed and current is displayed on LCD. Three phase $0.37 \mathrm{~kW}$ motor shown in figure $4-\mathrm{b}$ is used.

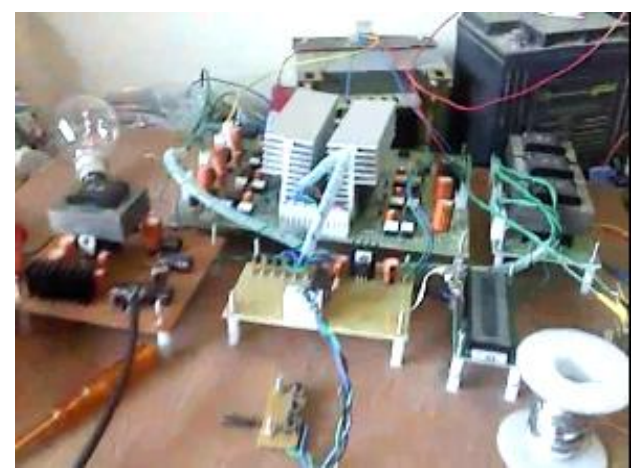

Fig 4-a: Three phase VSI

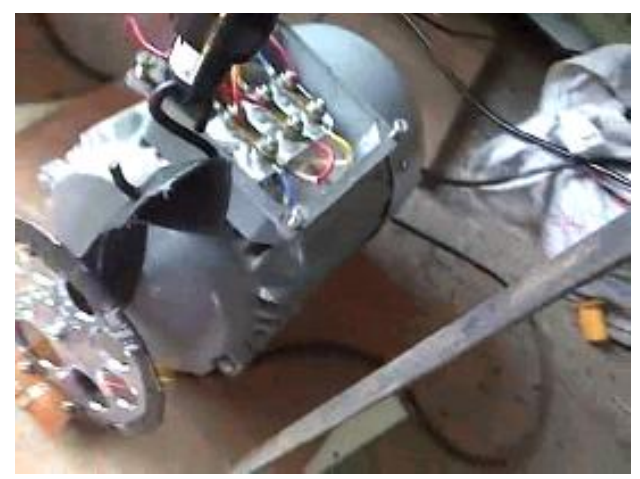

Fig 4-b: Three phase induction motor

Table 2: Tested Motor Parameters

\begin{tabular}{|c|c|}
\hline PARAMETERS & VALUES \\
\hline Rated Voltage & $415 \mathrm{~V} \pm 5 \%$ \\
\hline Rated Current & $1.05 \mathrm{~A}$ \\
\hline Rated Output Power & $0.37 \mathrm{~kW}$ \\
\hline Rated Frequency & $50 \mathrm{~Hz}$ \\
\hline Rated Speed & $1500 \mathrm{RPM}$ \\
\hline Power Factor & 0.82 \\
\hline
\end{tabular}

\section{CONCLUSION}

A dsPIC microcontroller based SPWM controlled three phase inverter fed Induction Motor drive has been designed and implemented successfully. The simulation and hardware implementation results are presented to verify the feasibility of the system robustness in relation to load torque variations while achieving the reference speed. The implementation of the developed work shows the practical industrial application.

\section{ACKNOWLEDGMENTS}

We would like to thank Prof. Mahmoud Riaz from the Department of Electrical and Computer Engineering, Minnesota University for permission of using his IM model at Simulink ${ }^{\circledR}$ file "im 3frames.mdl" available at the following website: 
http://www.ece.umn.edu/users/riaz/macsim/electricdrives.zip

\section{REFERENCES}

[1] K.R. Kumar, "Efficiency Optimization of Induction Motor Drive using Soft Computing Techniques", International Journal of Computer Applications (0975 8887), Volume 3 - No.1, June 2010

[2] Bimal K. Bose, "Modern Power Electronics and AC Drives," Pearson education.

[3] Leonhand.W, "Control of Electrical Drives," Springer Verlag, 1990

[4] A. Goedtel, I. N. da Silva and P. J. A. Serni, "Load torque identification in induction motor using neural networks technique", Electric Power Systems Research, vol. 77, no. 1, pp. 35-45, 2007.

[5] B. Lu, T. G. Habetler and R. G. Harley, "A survey of efficiency estimation methods for in-service induction motors", IEEE Transactions on Industry Applications, vol. 42, no. 4, pp. 924-933, 2006.

[6] D. Shi, P. J. Unsworth and R. X. Gao, "Sensorless speed measurement of induction motor using Hilbert transform and interpolated fast Fourier transform", IEEE Transactions on Instrumentation and Measurement, vol. 55, no. 1, pp. 290-299, 2006.

[7] S. Maiti, C. Chakraborty, Y. Hori and M.C. Ta, "Model reference adaptive controller-based rotor resistance and speed estimation techniques for vector controlled induction motor drive utilizing reactive power", IEEE Transactions on Industrial Electronics, vol. 55, no. 2, pp. 594-601, 2008

[8] F. Zidani, D. Diallo, M. E. H. Benbouzid and R. N-. Saïd, "A fuzzy-based approach for the diagnosis of fault modes in a voltage-fed PWM inverter induction motor drives", IEEE Transactions on Industrial Electronics, vol. 55, no. 2, pp. 586-593, 2008.

[9] P. P. Cruz and J. P. S. Paredes, "Artificial intelligence applications in direct torque control", The Fifth International Conference on Power Eletronics and Drive System (PEDS), vol. 2, pp. 1208-1212, 2003.
[10] B. Singh, G. Bhuvaneswari and B. Garg, "Harmonic mitigation in ACDC converters for vector controlled induction motor drives", IEEE Transactions on Energy Conversion, vol. 22, no. 3, pp. 637-646, 2007.

[11] B. Karanayil, M. F. Rahman and C. Grantham, "Online stator and rotor resistance estimation scheme using artificial neural networks for vector controlled speed sensorless induction motor drive", IEEE Transactions on Industrial Electronics, vol. 54, no. 1, pp. 167-176, 2007.

[12] A. Paladugu and B. H. Chowdhury, "Senseless control of inverter-fed induction motor drives", Electric Power Systems Research, vol. 77, no. 5-6, pp. 619-629, 2007.

[13] N. Islam, M. Haider and M. B. Uddin, "Fuzzy logic enhanced speed control system of a VSI-fed three phase induction motor", Proceedings of 2nd International Conference on Electrical and Electronics Engineering, pp. 296-301, 2005.

[14] S. Xiang-Dong, K. Kang-Hoon, Y. Byung-Gyu and M. Matsui, "Fuzzy logic- based V/f control of an induction motor for a DC grid power leveling system using flywheel energy storage equipment", IEEE Transactions on Industrial Electronics, vol. 56, no. 8, pp. 3161 3168,2009

[15] V. Chitra, and R. S. Prabhakar, "Induction Motor Speed Control using Fuzzy Logic Controller", World Academy of Science, Engineering and Technology 232006

[16] Marcelo Suetake, Ivan N. da Silva," Embedded DSPBased Compact Fuzzy System and Its Application for Induction Motor V/f Speed Control”, IEEE Transactions on Industrial Electronics, March 9, 2010.

[17] Hassan BaghgarBostan Abad, "Using Fuzzy Controller in Induction Motor Speed Control with Constant Flux", World Academy of Science, Engineering and Technology 112005

[18] L. A. Zadeh, Fuzzy sets. Information and control, Vol. 8, Academic, New York, 1965, pp 338_353.

[19] M. Riaz, "Simulation of electric machine and drive systems using Matlab and Simulink", November 6, 2011. 